\title{
Economic theory and econometric practice
}

\section{parametric efficiency analysis}

Sauer, Johannes

Published in:

Empirical Economics

DOI:

10.1007/s00181-006-0068-3

Publication date:

2006

Document version

Publisher's PDF, also known as Version of record

Citation for published version (APA):

Sauer, J. (2006). Economic theory and econometric practice: parametric efficiency analysis. Empirical Economics, 31(4), 1061-1087. https://doi.org/10.1007/s00181-006-0068-3 


\title{
Economic theory and econometric practice: parametric efficiency analysis
}

\author{
Johannes Sauer
}

Received: 15 November 2004 / Accepted: 15 December 2005

(C) Springer-Verlag 2006

\begin{abstract}
Parametric efficiency analysis is one of the most investigated areas in applied production economics. Nevertheless, the vast majority of empirical studies are not accompanied by a thorough theoretical interpretation of the underlying functional form and the obtained estimates. The robustness of policy suggestions based on inferences from efficiency measures nevertheless crucially depends on theoretically well-founded estimates. This research contribution adresses parametric efficiency measurement by critically reviewing the theoretical consistency of recently published technical efficiency estimates. The theoretical concerns are verified by empirical applications confirming the need for a posteriori checking the regularity of the estimated frontier by the researcher and, if necessary, the a priori imposition of the theoretical requirements. Bootstrapping based stochastic simulations of a simple parametric efficiency model by using different flexible functional forms confirmed the severeness of the theoretical concerns especially with respect to the merely locally restrictable translog specification.
\end{abstract}

Keywords Flexible functional forms - Parametric efficiency measurement . Regularity

\section{Introduction}

Parametric efficiency analysis is one of the most investigated areas in applied production economics. Here the stochastic production frontier model dominates the empirical literature of efficiency measurement. The availability of

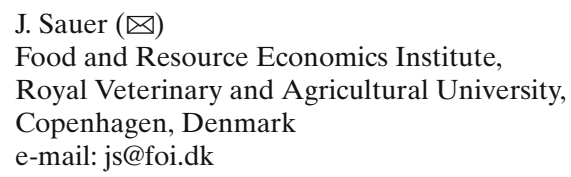


estimation software - freely distributed via the internet and relatively easy to use - recently inflated the number of corresponding applications. Nevertheless, the econometric applications provided by these 'black box'-tools are mostly not accompanied by a thorough theoretical interpretation of the underlying functional form and the obtained estimates. A critical assessment with respect to the evidence on theoretical consistency, flexibility and the choice of the appropriate functional form is missing for the vast majority of studies. The effectiveness and robustness of policy suggestions based on inferences from efficiency measures nevertheless crucially depends on proper estimates.

This contribution aims to show the importance of testing for the regularities of an estimated efficiency frontier based on flexible functional forms. The basic results of the discussion on theoretical consistency and functional flexibility are therefore reviewed and briefly applied to the translog production function. Subsequently parametric efficiency measurement is discussed to the background of these findings and essential implications are shown (Sect. 2). In the empirical part of the paper (Sect. 3) some randomly selected frontier applications are reviewed with respect to their theoretical consistency. Further different flexible functional forms are tested with respect to the effect on the efficiency estimates by a priori restricting them to functional regularity. Finally bootstrapping procedures are applied to investigate the robustness of regularity regions as well as the relative efficiency estimates.

\section{Theoretical considerations}

\subsection{Consistency, flexibility and applicability}

With respect to the empirical investigation of the relations between different dependent and independent variables the applied economist has to specify the mathematically described functional form of the relations investigated. Further the researcher has to specify a probability distribution for the stochastic residual $\varepsilon$. These two major assumptions about the underlying functional form and the probability distribution of the error term are usually considered as maintained hypotheses (see Fuss et al. 1978). For the ex ante selection of an algebraic form with respect to the particular economic relationship Lau's (1978, 1986) criteria can be used as a general guideline. He lists the following: (1) theoretical consistency: the algebraic functional form chosen must be capable of possessing all of the theoretical properties required for an appropriate choice of parameters. With respect to a production possibility set this would mean that the relationship is single valued, monotone increasing as well as quasi-concave implying that the input set is required to be convex. ${ }^{1}$ (2) domain of applicability: most commonly the domain of applicability refers to the set of values of the

\footnotetext{
${ }^{1}$ In the following we only consider a production function relationship. However, the same arguments apply for a cost, profit, return or distance function each showing different exogenous variables. A general discussion would require relatively complex arguments without providing any further insights.
} 
independent variables $x_{i}$ over which the algebraic functional form satisfies all the requirements for theoretical consistency. Lau (1986) refers to this concept as the extrapolative domain since it is defined on the space of the independent variables with respect to a given value of the vector of parameters $\beta_{i}{ }^{2}$ If, for given $\beta_{i}$, the algebraic functional form $f\left(x_{i}, \beta_{i}\right)$ is theoretically consistent over the whole of the applicable domain, it is said to be globally theoretically consistent or globally valid over the whole of the applicable domain. Fuss et al. (1978) stress the interpolative robustness as the functional form should be well-behaved in the range of observations, consistent with maintained hypotheses and admit computational procedures to check those properties, as well as the extrapolative robustness as the functional form should be compatible with maintained hypotheses outside the range of observations to be able to forecast relations. (3) flexibility: a flexible algebraic functional form is able to approximate arbitrary but theoretically consistent economic behaviour through an appropriate choice of the parameters. ${ }^{3}$ The production function can be said to be second-order flex$i b l e$ if at any given set of non-negative (positive) inputs the parameters $\beta$ can be chosen so that the derived input demand functions and the derived elasticities are capable of assuming arbitrary values at the given set of inputs subject only to theoretical consistency. ${ }^{4}$ (4) computational facility: this criteria implies the properties of 'linearity-in-parameters', 'explicit representability', 'uniformity' and 'parsimony'. For estimation purposes the functional form should therefore be linear-in-parameters, possible restrictions should be linear. Different functions in the same system should have the same 'uniform' algebraic form but differ in parameters. In order to achieve a desired degree of flexibility the functional form should be parsimonous with respect to the number of parameters. This to avoid methodological problems as multi-collinearity and a loss of degrees of freedom. (5) factual conformity: the functional form should be finally consistent with established empirical facts with respect to the economic problem to be modelled.

The concept of functional flexibility is commonly regarded as essential with respect to the choice of the functional form. The latter can be denoted as 'flexible' if its shape is only restricted by theoretical consistency implying the absence of unwanted a priori restrictions. Algebraically this can be formulated as follows: if $F(\beta, \mathbf{x})$ is an algebraic form for a real-valued function including variables $\mathbf{x}$ and a vector of unknown parameters $\beta$. F shall approximate the function value $F$, the gradient $F^{\prime}$ and the Hessian $F^{\prime \prime}$ of an unknown function

\footnotetext{
2 The set of $k$ 's for which a given functional form $f(x, \beta(k)) \equiv f(x, k)$ will have a domain of theoretical consistency (in $x$ ) that contains the prespecified set of $x$ 's is consequently called the interpolative domain of the functional form.

3 Alternatively flexibility can be defined as the ability to map different production structures at least approximately without determining the parameters by the functional form. The concept of flexibility was first introduced by Diewert $(1973,1974)$, Lau (1986) and Chambers (1988) discuss local and global approximation characteristics with respect to different functional forms.

4 This implies that the gradient as well as the Hessian matrix of the production function with respect to the inputs are capable of assuming arbitrary non-negative and negative semidefinite values respectively.
} 
$\bar{F}(\boldsymbol{x})$ at an arbitrary $\overline{\mathbf{x}}$. Flexibility of $F$ implies and is implied by the existence of a solution $\beta\left(\overline{\mathbf{x}} ; \bar{F}, \bar{F}^{\prime}, \bar{F}^{\prime \prime}\right)$ to the following set of equations: ${ }^{5}$

$$
F(\beta ; \overline{\mathbf{x}})=\bar{F}, \quad \nabla F(\beta ; \overline{\mathbf{x}})=\bar{F}^{\prime}, \quad \nabla^{2} F(\beta ; \overline{\mathbf{x}})=\bar{F}^{\prime \prime}
$$

with respect to certain consistency conditions on the variables $\boldsymbol{x}$ and possible values $\bar{F}, \bar{F}^{\prime}, \bar{F}^{\prime \prime}$ depending on the behavioural function $F$ is representing. Due to our production framework $F$ denotes a production function, therefore the solution is subject to non-negativity of $\overline{\mathbf{x}}, \bar{F}$ and $\bar{F}^{\prime}$ as well as negative semi-definiteness of $\bar{F}^{\prime \prime}$ such that $\bar{F}=\overline{\mathbf{x}} \bar{F}^{\prime}$ and $\bar{F}^{\prime \prime} \overline{\mathbf{x}}=0$. Hence for an arbitrary vector of exogeneous variables $\overline{\mathbf{x}}$, a vector $\beta$ exists such that the value of the function, its gradient as well as its Hessian matrix are equal to some $\bar{F}, \bar{F}^{\prime}, \bar{F}^{\prime \prime}$. The set of $\bar{F}, \bar{F}^{\prime}, \bar{F}^{\prime \prime}$ for which this is true includes all possible theoretically consistent values. Due to this framework, a flexible functional form can provide a local second order approximation of an arbitrary function, either formulated as a differential approximation, as a Taylor series or as a numerical approximation. Hence this form is called 'locally flexible'. With respect to a single-product technology with an $n$-dimensional input vector, a function exhaustively characterizing all of its relevant aspects should contain information about the quantity produced (one level effect), all marginal productivities ( $n$ gradient effects) as well as all substitution elasticities ( $n^{2}$ substitution effects). As the latter are symmetric beside the main diagonal with $n$ elements, only half of the off-diagonal elements are needed, i.e. $1 / 2 n(n-1)$. The number of effects an adequate single-output technology function should be capable of depicting independently of each other and without a priori restrictions amounts to a total of $1 / 2(n+2)(n+1)$. Hence a valid flexible functional form must contain at least $1 / 2(n+2)(n+1)$ independent parameters.

The relation between the supposed true function and the corresponding flexible estimation function can be described by the following hypotheses (see Morey 1986).

1. The estimation function is a local approximation of the true function: this simply means that the approximation properties of flexible functional forms are only locally valid and therefore value, gradient and Hessian of true and estimated function are equal at a single point of approximation (see Fig. 1). As only a local interpretation of the estimated parameters is possible, the forecasting capabilities with respect to variable values relatively distant from the point of approximation are severly restricted. ${ }^{6}$ In this case e.g. at least the necessary condition of local concavity with respect to global concavity can be tested for every point of approximation (see Sect. 3). ${ }^{7}$

\footnotetext{
5 Where the vertical bars denote the numerical value of the respective terms, determined at $\overline{\mathbf{x}}$.

${ }^{6}$ In the immediate neighbourhood of the approximation point each flexible functional form provides theoretically consistent parameters only if the true structure is theoretically consistent (see Morey 1986; Chambers 1988).

7 Morey (1986) raises the question about the location of the approximation point and stresses that there is no way to infer from the approximation function to the location of the approximation point.
} 


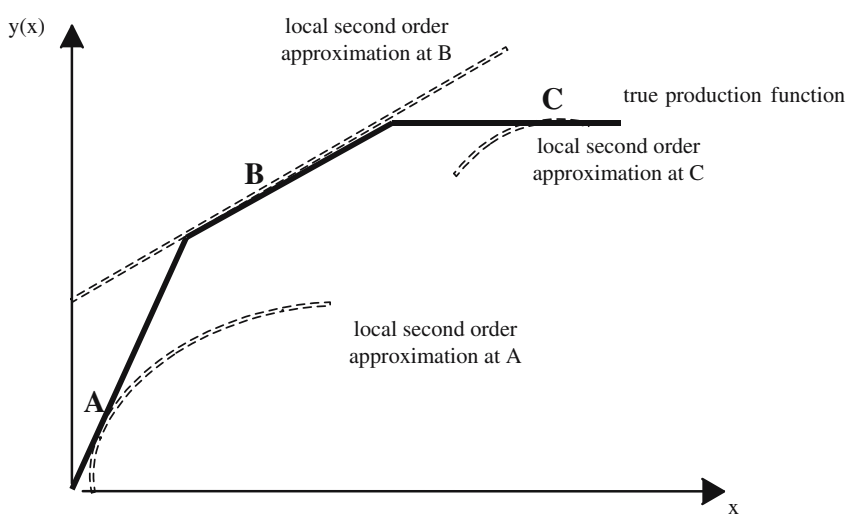

Fig. 1 Local approximation

2. The estimated function and the true structure are of the same functional form but show the desired properties only locally: most common flexible functions can either not be restricted to a well-behaved function without losing their flexibility (e.g., the translog function) or cannot be restricted to regularity at all. Points of interest in the true structure can be examined by testing the respective points in the estimation function. However, a positive answer to the question whether the estimation function and the true structure are still consistent with the properties of a well-behaved production function if the data does not equal the examined data set is highly uncertain. This uncertainty can only be illuminated by systematically testing all possible data sets.

3. The estimated function and the true structure are of the same functional form and show the desired properties globally: a flexible functional form which can be restricted to global regularity without losing its flexibility allows for the inference from the estimation function to the true structure and hence allows for meaningful tests of significance as the model is theoretically well founded (see Morey 1986). ${ }^{8}$ This approach of a flexible functional form promotes a concept of flexibility where the functional form has to fit the data to the greatest possible extent, subject only to the regularity conditions following from economic theory and independently depicting all economically relevant aspects (see Fig. 2).

Hence, it is evident that the quality of the estimation results crucially depends on the choice of the functional form. However, Lau (1978) notes that one should not expect to find an algebraic functional form satisfying all of these criteria (Lau's 'incompatibility theorem'). He suggests the domain of applicability as

Commonly, the point of approximation is held to be located at some mean of variables over all observations.

8 On the other side, a serious problem arises for the postulates of economic theory if a properly specified flexible function which is globally well-behaved is not supported by the data (see Feger 2000). 


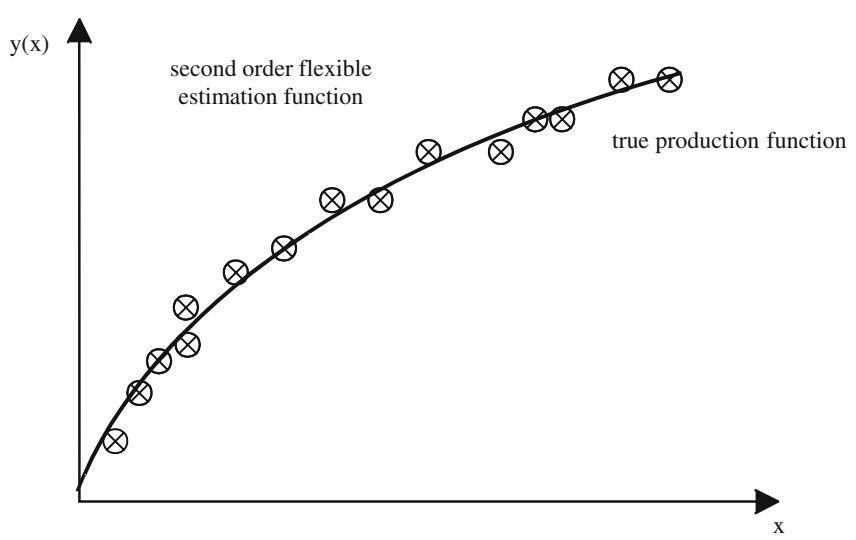

Fig. 2 Global approximation

the only area left for compromises with respect to the functional choice. ${ }^{9}$ For most functional forms there is a fundamental trade-off between flexibility and theoretical consistency as well as the domain of applicability. Production economists propose two solutions to this problem, depending on what kind of violation shows to be more severe: (1) the choice of functional forms which could be made globally theoretical consistent by corresponding parameter restrictions, here the range of flexibility has to be investigated; (2) to opt for functional flexibility and check or impose theoretical consistency for the proximity of an approximation point only. However, a globally theoretical consistent as well as flexible functional form can be considered as an adequate representation of the production possibility set. Locally theoretical consistent as well as flexible functional forms can be considered as an i-th order differential approximation of the true production possibilities.

\subsection{A translog production function}

As a prominent textbook example as well as one of the most often used functional forms with respect to efficiency measurement the translog production function has to be noted:

$$
f(x)=a_{0}+\sum_{i=1}^{n} a_{i} \ln x_{i}+\frac{1}{2} \sum_{i=1}^{n} \sum_{j=1}^{n} a_{i j} \ln x_{i} \ln x_{j}
$$

where symmetry of all Hessians by Young's theorem implies that $\alpha_{i j}=\alpha_{j i}$. It has $\left(n^{2}+3 n+2\right) / 2$ distinct parameters and hence just as many as required

9 Hence, even if a functional form is not globally theoretically consistent, it can be accomodated to be theoretically consistent within a sufficiently large subset of the space of independent variables. Even so it has to be stressed that the surest way to obtain a theoretically consistent representation of the technology is to make use of a dual concept such as the profit, cost or revenue function. 
to be flexible. The theoretical properties of the second order translog are well known (see e.g. Lau 1986): it is easily restrictable for global homogeneity as well as homotheticity, correct curvature can be implemented only locally if flexibility should be preserved, the maintaining of global monotonicity is impossible without losing second order flexibility. Hence, the translog functional form is fraught with the problem that theoretical consistency can not be imposed globally. The monotonicity condition holds for the translog specification if the following equation is positive:

$$
\frac{\partial y}{\partial x_{i}}=\frac{y}{x_{i}} * \frac{\partial \ln y}{\partial \ln x_{i}}=\frac{y}{x_{i}} *\left(a_{i}+\sum_{j=1}^{n} a_{i j} \ln x_{j}\right)>0
$$

Since both $y$ and $x_{\mathrm{i}}$ are positive numbers, monotonicity depends on the sign of the term in parenthesis, i.e. the elasticity of $\mathrm{y}$ with respect to $x_{\mathrm{i}}$. If it is assumed that markets are competitive and factors of production are paid their marginal products, the term in parenthesis equals the input $i$ 's share of total output, $s_{i}$. However, until most recent studies the issue of assuring monotonicity was neglected. Barnett et al. (1996) e.g. showed that the monotonicity requirement is by no means automatically satisfied for most functional forms, moreover violations are frequent and empirically meaningful. ${ }^{10} \mathrm{By}$ adhering to the law of diminishing marginal productivities, marginal products, apart from being positive should be decreasing in inputs implying the fulfillment of the following expression:

$$
\frac{\partial^{2} y}{\partial x_{i}^{2}}=\left[a_{i i}+\left(a_{i}-1+\sum_{j=1}^{n} a_{i j} \ln x_{j}\right) *\left(a_{i}+\sum_{j=1}^{n} a_{i j} \ln x_{j}\right)\right] *\left(y / x_{i}^{2}\right)<0
$$

Again, this depends on the nature of the terms in parenthesis. However, both restrictions (i.e. $\partial y / \partial x_{i}>0$ and $\partial^{2} y / \partial x_{i}^{2}<0$ ) should hold at least at the point of approximation.

The necessary and sufficient condition for a specific functional curvature consists in the semi-definiteness of its bordered Hessian matrix as the Jacobian of the derivatives $\partial y / \partial x_{i}$ with respect to $x_{i}$ : if $\nabla^{2} Y(x)$ is negatively semi-definite, $Y$ is quasi-concave, where $\nabla^{2}$ denotes the matrix of second order partial derivatives with respect to $(\bullet)$ (see Appendix). The conditions of quasi-concavity are related to the fact that this property implies a convex input requirement set (see in detail e.g. Chambers 1988). The most operational way of testing square numerical matrices for semi-definiteness is the eigen - or spectral decomposition: let $\mathbf{A}$ be a square matrix. If there is a vector $\mathbf{X} \in \mathrm{R}^{\mathrm{n}} \neq 0$ such that

10 Barnett (2002) notes: "In specifications of tastes and technology, econometricians often impose curvature globally, but monotonicity only locally or not at all. In fact monotonicity rarely is even mentioned in that literature. But without satisfaction of both curvature and monotonicity, the second-order conditions for optimizing behaviour fail, and duality theory fails." (p. 199). 


$$
\boldsymbol{A} \boldsymbol{X}=\lambda \boldsymbol{X}
$$

for some scalar $\lambda$, then $\lambda$ is called the eigenvalue of $\mathbf{A}$ with the corresponding eigenvector $\mathbf{X}$. Following this procedure the magnitude of the $m+n$ eigenvalues of the bordered Hessian have to be determined. With respect to the translog production function curvature depends on the input bundle with $f_{i j}$ as the second cross-derivative

$$
\frac{\partial^{2} y}{\partial x_{i} \partial x_{j}}=\left[a_{i j}+\left(a_{i}+\sum_{j=1}^{n} a_{i j} \ln x_{j}\right) *\left(a_{j}+\sum_{i=1}^{n} a_{i j} \ln x_{i}\right)\right] *\left(y / x_{i} x_{j}\right)<0
$$

For some bundles quasi-concavity may be satisfied but for others not and hence what can be expected is that the condition of negative-semidefiniteness of the bordered Hessian is met only locally or with respect to a range of bundles. It became clear that there is a a trade-off between flexibility and theoretical consistency with respect to the translog as well as most flexible functional forms. Economists propose different solutions to this problem:

1. Imposing globally theoretical consistency destroys the flexibility of the translog as well as other second-order flexible functional forms, ${ }^{11}$ as e.g. the generalized Leontief. However, theoretical consistency can be locally imposed on these forms by maintaining their functional flexibility. Further, Ryan and Wales (2000) even argue that a sophisticated choice of the reference point could lead to satisfaction of consistency at most or even all data points in the sample. ${ }^{12}$ Jorgenson and Fraumeni (1981) firstly propose the imposition of quasi-concavity through restricting $\mathbf{A}$ to be a negative semidefinite matrix.

Imposing curvature at a reference point (usually the sample mean) is attained by setting $a_{i j}=-\left(\mathbf{D D}^{\prime}\right)_{i j}+a_{i} \delta_{i j}+a_{i} a_{j}$ where $i, j=1, \ldots, n, \delta_{i j}=1$ if $i=j$ and 0 otherwise and $(\mathbf{D D})_{i j}$ as the ij-th element of $\left(\mathbf{D D}^{\prime}\right)_{i j}$ with $\mathbf{D}$ a lower triangular matrix. The approximation point could be the data mean. However, the procedure is a little bit different. First, all data are divided by their mean. This transfers the approximation point to an $(n+1)$-dimensional vector of ones. At the approximation point the terms in (3) and (6) do not depend on the input bundle anymore. It can be expected that input bundles in the neighbourhood also provide the desired output. The transformation even moves the observation towards the approximation point and thus increases the likelihood of getting theoretically consistent results (see Ryan and Wales 2000). Imposing curvature globally is attained by setting $a_{i j}=-(\mathbf{D D})_{i j}$. Alternatively one can

11 Second-order flexibility in this context refers to Diewert's (1974) definition where a function is flexible if the level of production (cost or profit) and all of its first and second derivatives coincide with those of an arbitrary function satisfying linear homogeneity at any point in an admissable range.

12 In fact Ryan and Wales $(1998,1999,2000)$ could confirm this for several functional forms in a consumer demand context as well as for the translog and generalized Leontief specification in a producer context. See also Feger (2000) and the example by Terrell (1996). 
use Lau's (1978) technique by applying the Cholesky factorization $\mathbf{A}=-\mathbf{L B} \mathbf{L}^{\prime}$ where $\mathbf{L}$ is a unit lower triangular matrix and $\mathbf{B}$ as a diagonal matrix. However, the elements of $\mathbf{D}$ and $\mathbf{L}$ are nonlinear functions of the decomposed matrix, and consequently the resulting estimation function becomes nonlinear in parameters. Hence, linear estimation algorithms are ruled out even if the original function is linear in parameters.

However, by imposing global consistency on the translog functional form Diewert and Wales (1987) note that the parameter matrix is restricted leading to seriously biased elasticity estimates. Hence, the translog function would lead its flexibility. Any flexible functional form can be restricted to convexity or (quasi-)concavity with the above method -i.e. to local convexity or (quasi-)concavity. The Hessian of most flexible functional forms are not structured in a way that the definiteness property is invariant towards changes in the exogenous variables (see Jorgenson and Fraumeni 1981).

2. Functional forms can be chosen which could be made globally theoretical consistent through corresponding parameter restrictions and by simultaneously maintaining flexibility. This is shown for the symmetric generalized McFadden cost function by Diewert and Wales (1987) following a technique initially proposed by Wiley et al. (1973). Like the generalized Leontief, the symmetric generalized McFadden is linearily homogenous in prices by construction, monotonicity can either be implemented locally only or, if restricted for globally, the global second-order flexibility is lost (as impressively shown by Barnett 2002). However, if this functional form is restricted for correct curvature the curvature property applies globally. ${ }^{13}$ Other models as the semi-nonparametrically estimated Almost Ideal Model (AIM) or the generalized symmetric Barnett model (including the generalized McFadden) could show even better regularity properties. Furthermore regular regions following Gallant and Golups (1984) numerical approach to account for consistency by using e.g. Bayesian techniques can be constructed with respect to flexible functional forms. ${ }^{14}$

\subsection{Parametric efficiency measurement}

The technical and allocative efficiency of netput bundles have been received primary interest by production economists in the recent years. This trend is accompanied by a shift in the interpretation insofar as the estimated results are not interpreted for the approximation point but for all input values. While it is possible to investigate the structure of the production possibilities at any virtual production plan, efficiency considerations can only be made for the individual

\footnotetext{
13 Unfortunately, the second order flexibility property is in this case restricted to only one point.

14 To avoid the disturbing choice between inflexible and inconsistent specifications this approach imposes theoretical consistency only over the set of variable values where inferences will be drawn. Here the model parameters are restricted in a way that the resulting elasticities meet the requirements of economic theory for the whole range of variable constellations that are a priori likely to occur, i.e. a regular region is created.
} 
observations. However, this in turn requires that the properties of the production function have to be investigated for every observable netput vector. The consequences of a violation of theoretical consistency for the relative efficiency evaluation will be discussed using Figs. 3 and 4 by showing the effect on the random error term.

As becomes clear the estimated relative inefficiency equals the relative inefficiency for the production unit A with respect to the real production function.

Fig. 3 Violation of monotonicity

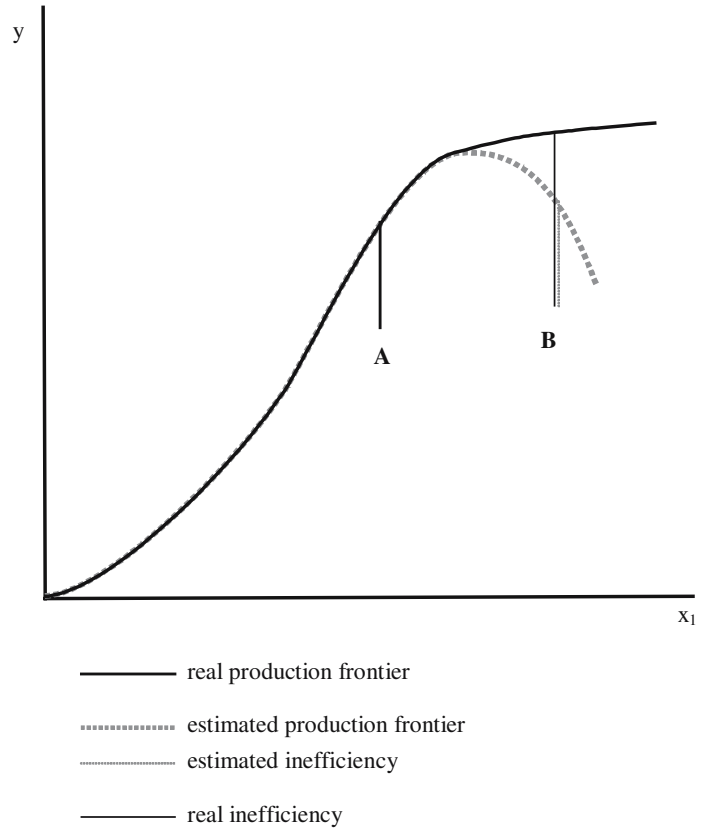

Fig. 4 Violation of quasi-concavity

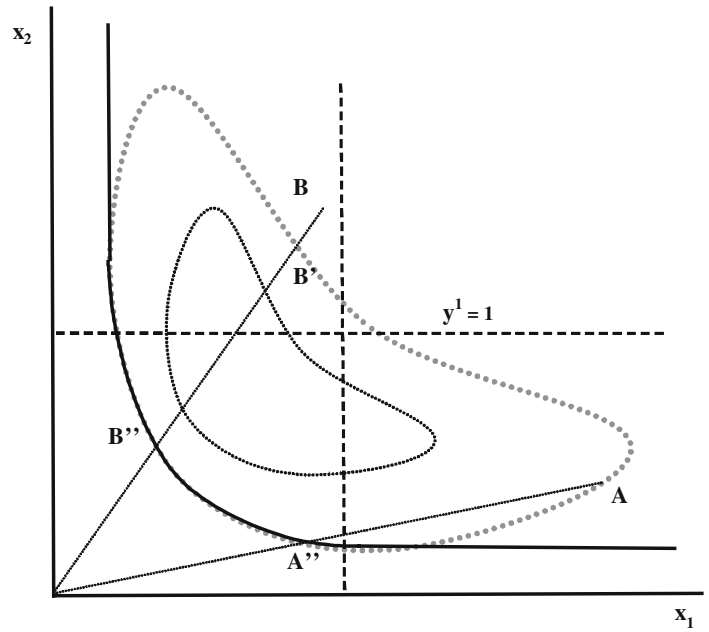


As the estimated function violates the monotonicity critera for parts of the function the estimated relative inefficiency of production unit B understates the real inefficiency for this observation. Figure 4 shows the implications as a result of irregular curvature of the estimated efficiency frontier.

The dotted line describes an isoquant of the estimated production function. The relative inefficiency of the input combination at production unit $\mathrm{B}$ measured against the estimated frontier (at $B^{\prime}$ ) understates the real inefficiency which is obtained by measuring the input combination against the real production frontier at point $B^{\prime \prime}$. Observation A lies on the estimated isoquant and is therefore measured as full efficient (point A). Nevertheless this production unit produces relatively inefficient with respect to the real production frontier (see point $A^{\prime \prime}$ ). The graphical discussion shows the implications for efficiency measurement: theoretical inconsistent frontiers over- or understate real relative inefficiency and hence lead to severe misperceptions and finally inadequate as well as counterproductive policy measures with respect to the individual production unit in question. However, a few applications exist considering the need for theoretical consistent frontier estimation. ${ }^{15}$ Here global curvature correctness is assured by maintaining functional flexibility. However, the vast majority of existing efficiency studies uses the error components approach by applying an inflexible CobbDouglas production function or a flexible translog production function without checking or imposing monotonicity as well as quasi-concavity requirements.

\section{Empirical considerations}

\subsection{Testing for local consistency a posteriori}

Theoretical consistency of the estimated function should be ideally tested for all points of observation which requires e.g. for the translog specification beside the parameters of estimation also the output and input data on every observation. Most contributions fail to satisfactorily document the applied data set at least with respect to the sample means. However, the following analysis uses a number of translog production function applications published in recent years focusing on agriculture related issues. Here monotonicity - via the gradient of the function with respect to each input by investigating the first derivatives - as well as quasi-concavity - via the bordered Hessian matrix with respect to the input bundle by investigating the eigenvalues - are checked for the individual local approximation point at the sample mean:

\footnotetext{
15 See Khumbhakar (1989), Pierani and Rizzi (1999), Christopoulos et al. (2001), Craig et al. (2003) as well as Sauer and Frohberg (2006) estimated a symmetric generalized McFadden cost frontier by imposing concavity and checking for monotonicity. Whereas Kumbhakar, Christopoulos et al. as well as Sauer and Frohberg uses a non-radial approach, Craig et al. uses a shadow cost frontier to efficiency measurement. O'Donnell (2002) applies Bayesian methodology to impose regularity constraints on a system of equations derived from a translog shadow cost frontier.
} 
- Kumbhakar and Hjalmarrson (1993) investigated the efficiency of 608 Swedish farms engaged in milk production for the period 1968-1975 considering labor, material, land and capital as inputs. All first derivatives with respect to inputs showed positive signs at the sample mean and therefore fulfilled the monotonicity criterion. However, the second derivative with respect to land revealed to be non-negative and therefore indicates non-observance of the law of diminishing productivity. Hence checking the eigenvalues of the corresponding bordered Hessian matrix, the latter turned out to be not negative semi-definite and the estimated production frontier does not fulfill the curvature criterion of quasi-concavity (see Table 1 for the results of the regularity tests and Table 2 for the numerical details of the tests performed).

- Kumbhakar and Heshmati (1995) estimated technical efficiency for a panel of Swedish Dairy Farms by a multi-step approach. They used fodder, material, labor, capital, grass fodder, cultivated land, pasture land as well as the age of the farmers as input variables. Evaluated at the sample mean only three of eight inputs fulfilled the monotonicity requirement. The estimated function showed not be quasi-concave (see Table 3 and 4).

- Battese and Broca (1997) estimated technical efficiencies of 109 wheat farmers in Pakistan over the period 1986-1991 using land, labor, fertilizer and

Table 1 Example I - regularity

\begin{tabular}{lllll}
\hline Input & Monotonicity & $\begin{array}{l}\text { Diminishing } \\
\text { Marginal } \\
\text { Productivity }\end{array}$ & $\begin{array}{l}\text { Quasi-concavity } \\
\text { (input bundle) }\end{array}$ & $\begin{array}{l}\text { Local regularity } \\
\text { (monoton and quasi-concave) }\end{array}$ \\
\hline Labor & F & F & NF & NF \\
Material & F & F & & \\
Land & F & NF & & \\
Capital & F & F & & \\
\hline
\end{tabular}

Kumbhakar and Hjalmarrson (1993), Sweden, 608 observations, period: 1968-1975, output variable: dairy output

F fulfilled, NF not fulfilled

Table 2 Example I - numerical details of regularity tests

\begin{tabular}{|c|c|c|c|}
\hline Input & $\begin{array}{l}\text { Monotonicity } \\
\text { first derivatives }\end{array}$ & $\begin{array}{l}\text { Diminishing marginal } \\
\text { productivity second } \\
\text { derivatives }\end{array}$ & $\begin{array}{l}\text { Quasi-concavity } \\
\text { eigenvalues of bordered } \\
\text { hessian matrix }\end{array}$ \\
\hline Labor & 0.07571 & -0.00002 & $\begin{array}{l}\text { E1: }-0.58005 \\
\text { E2: } \mathbf{0 . 0 0 0 7 9}, \text { E3: }-181.13829 \\
\text { E4: } \mathbf{0 . 6 3 6 2 7}, \text { E5: } \mathbf{1 8 1 . 1 3 8 4 9}\end{array}$ \\
\hline Material & 1.76208 & -0.00487 & \\
\hline Land & 0.60774 & 0.06243 & \\
\hline Capital & 0.26717 & -0.00033 & \\
\hline
\end{tabular}

Not consistent with economic theory indicated in bold 
Table 3 Example II - regularity

\begin{tabular}{lllll}
\hline Input & Monotonicity & $\begin{array}{l}\text { Diminishing } \\
\text { Marginal } \\
\text { Productivity }\end{array}$ & $\begin{array}{l}\text { Quasi-concavity } \\
\text { (input bundle) }\end{array}$ & $\begin{array}{l}\text { Local regularity } \\
\text { (monoton and quasi-concave) }\end{array}$ \\
\hline Fodder & $\mathrm{NF}$ & $\mathrm{NF}$ & $\mathrm{NF}$ & $\mathrm{NF}$ \\
Material & $\mathrm{NF}$ & $\mathrm{NF}$ & & \\
Labor & $\mathrm{F}$ & $\mathrm{F}$ & & \\
Capital & $\mathrm{NF}$ & $\mathrm{NF}$ & \\
Grass & $\mathrm{F}$ & $\mathrm{F}$ & & \\
Land & $\mathrm{F}$ & $\mathrm{F}$ & $\mathrm{F}$ & \\
Pasture & $\mathrm{NF}$ & $\mathrm{F}$ & & \\
Age & $\mathrm{NF}$ & $\mathrm{F}$ & & \\
\hline
\end{tabular}

Kumbhakar and Heshmati (1995), Sweden, 4890 observations, period: 1976-1988, output variable: dairy output

F fulfilled, NF not fulfilled

Table 4 Example II - numerical details of regularity tests

\begin{tabular}{llll}
\hline Input & $\begin{array}{l}\text { Monotonicity } \\
\text { first derivatives }\end{array}$ & $\begin{array}{l}\text { Diminishing marginal } \\
\text { productivity second } \\
\text { derivatives }\end{array}$ & $\begin{array}{l}\text { Quasi-concavity } \\
\text { eigenvalues of } \\
\text { Bordered Hessian Matrix }\end{array}$ \\
\hline Fodder & $\mathbf{- 1 . 4 4 2 5 9}$ & $\mathbf{3 . 2 4 1 7 2 E}-\mathbf{0 5}$ & $\begin{array}{l}\text { E1: 2116.84741, E2: 46.42065, } \\
\text { E3: 0.04901, E4: }-1.55354 \mathrm{E}-06,\end{array}$ \\
& & & $\begin{array}{l}\text { E5: }-0.07129, \text { E6: }-0.00564, \\
\text { E7: }-2137.260, \text { E8: }-18.40785, \\
\end{array}$ \\
Material & $\mathbf{- 0 . 4 4 5 3 9}$ & $\mathbf{2 . 3 6 8 3 4 E - 0 5}$ & E9: -68.18484 \\
Labor & 0.189542 & $-1.33923 \mathrm{E}-06$ & \\
Capital & $\mathbf{- 0 . 5 9 1 4 9}$ & $\mathbf{1 . 0 4 8 2 9 E - 0 5}$ & \\
Grass & 8.5655 & -0.00516 & \\
Land & 1586.66 & -33.4089 & \\
Pasture & $\mathbf{- 1 4 0 8 . 6 2}$ & -0.86203 & \\
Age & $\mathbf{- 1 4 6 . 9 7 1}$ & -26.3370 & \\
\hline
\end{tabular}

Not consistent with economic theory in indicated in bold

seed as inputs. Model 1 evaluated at the sample mean failed to adhere to monotonicity and quasi-concavity (see Tables 5 and 6 ). ${ }^{16}$

- Brümmer and Loy (2000) analysed the relative technical efficiency of dairy farms in northern Germany for the period 1987-1994: both models estimated fulfilled monotonicity for all inputs but failed to adhere to diminishing marginal productivity as well as quasi-concavity. Tables 7 and 8 give the details for model1.

- Brümmer (2001) attempted to analyse the technical efficiency of 185 private farms in Slovenia for the years 1995 and 1996. For both years the estimated function showed to be non-monoton in the inputs land and intermediates.

$\overline{16}$ Model 2 failed to adhere to quasi-concavity. 
Table 5 Example III - regularity

\begin{tabular}{lllll}
\hline Input & Monotonicity & $\begin{array}{l}\text { Diminishing } \\
\text { marginal } \\
\text { productivity }\end{array}$ & $\begin{array}{l}\text { Quasi-concavity } \\
\text { (input bundle) }\end{array}$ & $\begin{array}{l}\text { Local regularity } \\
\text { (monoton and quasi-concave) }\end{array}$ \\
\hline Land & $\mathrm{F}$ & $\mathrm{F}$ & $\mathrm{NF}$ & $\mathrm{NF}$ \\
Labor & $\mathrm{NF}$ & $\mathrm{NF}$ & & \\
Fertiliser & $\mathrm{F}$ & $\mathrm{F}$ & & \\
Seed & $\mathrm{F}$ & $\mathrm{NF}$ & & \\
\hline
\end{tabular}

Battese and Broca (1997), Pakistan, 330 observations, period: 1986-1991, output variable: wheat output

F fulfilled, NF not fulfilled

Table 6 Example III - numerical details of regularity tests

\begin{tabular}{llll}
\hline Input & $\begin{array}{l}\text { Monotonicity } \\
\text { first derivatives }\end{array}$ & $\begin{array}{l}\text { Diminishing marginal } \\
\text { productivity second } \\
\text { derivatives }\end{array}$ & $\begin{array}{l}\text { Quasi-concavity } \\
\text { eigenvalues of } \\
\text { bordered Hessian matrix }\end{array}$ \\
\hline Land & 1115.82115 & -47.18914 & $\begin{array}{l}\text { E1: 1298.53011, } \\
\text { E2: }-1321.70761, \text { E3: 0.01271, } \\
\text { E4: }-0.02751, \text { E5: }-23.99859\end{array}$ \\
Labor & $-\mathbf{1 . 1 7 8 3 8}$ & $\mathbf{0 . 0 0 1 3 3}$ & \\
Fertiliser & 5.23465 & -0.01544 & \\
Seed & 26.37129 & $\mathbf{0 . 0 0 0 4 2}$ & \\
\hline
\end{tabular}

Not consistent with economic theory is indicated in bold

Table 7 Example IV - regularity

\begin{tabular}{lllll}
\hline Input & Monotonicity & $\begin{array}{l}\text { Diminishing } \\
\text { marginal } \\
\text { productivity }\end{array}$ & $\begin{array}{l}\text { Quasi-concavity } \\
\text { (input bundle) }\end{array}$ & $\begin{array}{l}\text { Local regularity } \\
\text { (monoton and quasi-concave) }\end{array}$ \\
\hline Capital & $\mathrm{F}$ & $\mathrm{F}$ & $\mathrm{NF}$ & $\mathrm{NF}$ \\
Land & $\mathrm{F}$ & $\mathrm{NF}$ & & \\
Labour & $\mathrm{F}$ & $\mathrm{F}$ & & \\
Intermediates & $\mathrm{F}$ & $\mathrm{NF}$ & $\mathrm{NF}$ & \\
Quota & $\mathrm{F}$ & $\mathrm{NF}$ & & \\
\hline
\end{tabular}

Brümmer and Loy (2000), Germany, 5093 observations, period: 1987-1994, output variable: dairy output

F fulfilled, NF not fulfilled

The estimated translog frontiers do not fulfill the curvature requirement of quasi-concavity (see Tables 9 and 10).

- Ajibefun et al. (2002) aimed to investigate factors influencing the technical efficiency of 67 crop farms in the Nigerian state of Oyo for the year 1995. The authors used land, labor, capital as well as hired labour to estimate a translog production frontier. However, the estimated function showed to be monoton in all inputs but not quasi-concave for the input bundle as Tables 11 and 12 document. 
Table 8 Example IV - numerical details of regularity tests

\begin{tabular}{|c|c|c|c|}
\hline Input & $\begin{array}{l}\text { Monotonicity } \\
\text { first derivatives }\end{array}$ & $\begin{array}{l}\text { Diminishing marginal } \\
\text { productivity } \\
\text { second derivatives }\end{array}$ & $\begin{array}{l}\text { Quasi-concavity } \\
\text { eigenvalues of } \\
\text { bordered Hessian matrix }\end{array}$ \\
\hline Capital & 1.74868 & -0.03126 & $\begin{array}{l}\text { E1: 10.70562, E2: }-0.95049 \\
\text { E3: 96.62495, E4: }-33.98629 \\
\text { E5: }-96.60718, \text { E6: }-0.00039\end{array}$ \\
\hline Land & 0.03524 & 0.01624 & \\
\hline Labour & 17.94161 & -24.20236 & \\
\hline Intermediates & 1.00768 & 0.00298 & \\
\hline Quota & 0.49772 & 0.00061 & \\
\hline
\end{tabular}

Not consistent with economic theory is indicated in bold

Table 9 Example V - Regularity

\begin{tabular}{lllll}
\hline Input & Monotonicity & $\begin{array}{l}\text { Diminishing } \\
\text { marginal } \\
\text { productivity }\end{array}$ & $\begin{array}{l}\text { Quasi-concavity } \\
\text { (input bundle) }\end{array}$ & $\begin{array}{l}\text { Local regularity } \\
\text { (monoton and } \\
\text { quasi-concave) }\end{array}$ \\
\hline Labor & $\mathrm{F}$ & $\mathrm{F}$ & $\mathrm{NF}$ & $\mathrm{NF}$ \\
Land & $\mathrm{NF}$ & $\mathrm{NF}$ & & \\
Intermediates & $\mathrm{NF}$ & $\mathrm{NF}$ & & \\
Capital & $\mathrm{F}$ & $\mathrm{NF}$ & & \\
\hline
\end{tabular}

Brümmer (2001), Slovenia, 185 observations, period: 1995/1996, output variable: total farm output F fulfilled, NF not fulfilled

Table 10 Example V - numerical details of regularity tests

\begin{tabular}{llll}
\hline Input & $\begin{array}{l}\text { Monotonicity } \\
\text { first derivatives }\end{array}$ & $\begin{array}{l}\text { Diminishing marginal } \\
\text { productivity second } \\
\text { derivatives }\end{array}$ & $\begin{array}{l}\text { Quasi-concavity } \\
\text { eigenvalues of } \\
\text { bordered Hessian matrix }\end{array}$ \\
\hline Land & 1474.20723 & -198.88438 & $\begin{array}{l}\text { E1: }-2.10927, \text { E2: }-240882.7599 \\
\text { E3: 1.93102E-06, E4: 240710.0172 } \\
\text { E5: 0.00681 }\end{array}$ \\
Labor & $\mathbf{- 0 . 0 5 9 2 1}$ & $\mathbf{3 . 3 4 7 8 6 E - 0 6}$ & \\
Fertiliser & $\mathbf{- 1 7 2 . 2 4 3 7 2}$ & $\mathbf{2 0 . 0 3 4 8 3}$ & \\
Seed & 5.12042 & $\mathbf{0 . 0 0 4 4 5}$ & \\
\hline
\end{tabular}

Not consistent with economic theory is in indicated in bold

- Alvarez and Arias (2004) tried to find evidence on the relationship between technical efficiency and the size of 196 dairy farms in Spain for the period 1993-1998. For the inputs labour and land the estimated frontier showed to be non-monoton at the sample means. The production frontier estimated is not curvature correct (see Tables 13 and 14).

- Finally Kwon and Lee (2004) estimated stochastic production frontiers for the years 1993-1997 with respect to Korean rice farmers. All efficiency frontiers showed to be non-monoton for the input fertilizer and do not fulfill the curvature requirement of quasi-concavity (See Tables 15 and 16). 
Table 11 Example VI - regularity

\begin{tabular}{lllll}
\hline Input & Monotonicity & $\begin{array}{l}\text { Diminishing } \\
\text { marginal } \\
\text { productivity }\end{array}$ & $\begin{array}{l}\text { Quasi-concavity } \\
\text { (input bundle) }\end{array}$ & $\begin{array}{l}\text { local regularity } \\
\text { (monoton and quasi-concave) }\end{array}$ \\
\hline Labor & $\mathrm{F}$ & $\mathrm{NF}$ & $\mathrm{NF}$ & $\mathrm{NF}$ \\
Land & $\mathrm{F}$ & $\mathrm{F}$ & & \\
Capital & $\mathrm{F}$ & $\mathrm{F}$ & & \\
Hired Labor & $\mathrm{F}$ & $\mathrm{F}$ & & \\
\hline
\end{tabular}

Ajibefun et al. (2002), Nigeria, 67 observations, period: 1995, output variable: total crop output $\mathrm{F}$ fulfilled, NF not fulfilled

Table 12 Example VI - numerical details of regularity tests

\begin{tabular}{llll}
\hline Input & $\begin{array}{l}\text { Monotonicity } \\
\text { first derivatives }\end{array}$ & $\begin{array}{l}\text { Diminishing marginal } \\
\text { productivity } \\
\text { second derivatives }\end{array}$ & $\begin{array}{l}\text { Quasi-concavity } \\
\text { eigenvalues of } \\
\text { bordered Hessian matrix }\end{array}$ \\
\hline Labor & 545.51798 & $\mathbf{3 2 5 . 5 9 6 8 2}$ & $\begin{array}{l}\text { E1: }-473.82527, \text { E2: 756.14889 } \\
\text { E3: }-0.61524, \text { E4: 41.48851 } \\
\text { E5: }-0.00035\end{array}$ \\
Land & 63.39966 & -0.07723 & \\
Capital & 210.64866 & -2.32279 & \\
Hired Labor & 1.22185 & -0.00026 & \\
\hline
\end{tabular}

Not consistent with economic theory is indicated in bold

Table 13 Example VII - regularity

\begin{tabular}{lllll}
\hline Input & Monotonicity & $\begin{array}{l}\text { Diminishing } \\
\text { marginal } \\
\text { productivity }\end{array}$ & $\begin{array}{l}\text { Quasi-concavity } \\
\text { (input bundle) }\end{array}$ & $\begin{array}{l}\text { local regularity } \\
\text { (monoton and quasi-concave) }\end{array}$ \\
\hline Labor & NF & NF & NF & NF \\
Cows & F & F & & \\
Feedstuff & F & NF & & \\
Land & NF & NF & NF & \\
Roughage & F & R & & \\
\hline
\end{tabular}

Alvarez and Arias (2004), Spain, 196 observations, period: 1993-1998, output variable: milk output F fulfilled, NF not fulfilled

To sum up: $100 \%$ of all arbitrarily selected translog production frontiers fail to fulfill (at least) local regularity at the sample means. Hence, as the investigated frontiers are flexible but not regular (at least at the sample mean) derived efficiency scores are not theoretical consistent and therefore are not an appropriate basis for the formulation of policy measures.

\subsection{Testing flexible functional forms by a priori imposition}

In order to demonstrate the theoretical concerns with respect to the econometric practice of constructing and estimating efficiency frontiers expressed so 
Table 14 Example VII - numerical details of regularity tests

\begin{tabular}{|c|c|c|c|}
\hline Input & $\begin{array}{l}\text { Monotonicity } \\
\text { first derivatives }\end{array}$ & $\begin{array}{l}\text { Diminishing Marginal } \\
\text { productivity } \\
\text { second derivatives }\end{array}$ & $\begin{array}{l}\text { Quasi-Concavity } \\
\text { eigenvalues of } \\
\text { bordered Hessian matrix }\end{array}$ \\
\hline Labor & $-\mathbf{1 3 8 4 8 . 6 3 7 8 5}$ & 3208.26404 & $\begin{array}{l}\text { E1: }-13276.23262, \text { E2: 16174.03199 } \\
\text { E3: }-116.13557, \text { E4: }-3.9745 E-05 \\
\text { E5: 889.68296, E6: 0.00672 }\end{array}$ \\
\hline Cows & 269.10386 & -11.85909 & \\
\hline Feedstuff & 2.70035 & $1.22526 \mathrm{E}-05$ & \\
\hline Land & -4609.10832 & 474.94612 & \\
\hline Roughage & 20.27928 & 0.00236 & \\
\hline
\end{tabular}

Not consistent with economic theory is indicated in bold

Table 15 Example VIII - Regularity (Here the results for the base model are reported.)

\begin{tabular}{lllll}
\hline Input & Monotonicity & $\begin{array}{l}\text { Diminishing } \\
\text { marginal } \\
\text { productivity }\end{array}$ & $\begin{array}{l}\text { Quasi-concavity } \\
\text { (input bundle) }\end{array}$ & $\begin{array}{l}\text { Local regularity } \\
\text { (monoton and quasi-concave) }\end{array}$ \\
\hline Land & $\mathrm{F}$ & $\mathrm{F}$ & $\mathrm{NF}$ & $\mathrm{NF}$ \\
Labor & $\mathrm{F}$ & $\mathrm{F}$ & & \\
Capital & $\mathrm{F}$ & $\mathrm{F}$ & & \\
Fertiliser & $\mathrm{NF}$ & $\mathrm{NF}$ & & \\
Pesticides & $\mathrm{F}$ & $\mathrm{F}$ & & \\
Others & $\mathrm{F}$ & $\mathrm{F}$ & & \\
\hline
\end{tabular}

Kwon and Lee (2004), Korea, 1026 observations, period: 1993-1997, output variable: rice output F fulfilled, NF not fulfilled

Table 16 Example VIII - Numerical Details of Regularity Tests

\begin{tabular}{|c|c|c|c|}
\hline Input & $\begin{array}{l}\text { Monotonicity } \\
\text { first derivatives }\end{array}$ & $\begin{array}{l}\text { Diminishing marginal } \\
\text { productivity } \\
\text { second derivatives }\end{array}$ & $\begin{array}{l}\text { Quasi-concavity } \\
\text { eigenvalues of } \\
\text { bordered Hessian matrix }\end{array}$ \\
\hline Labor & -13848.63785 & 3208.26404 & $\begin{array}{l}\text { E1: }-13276.23262, \text { E2: 16174.03199 } \\
\text { E3: }-116.13557, \text { E4: }-3.9745 E-05 \\
\text { E5: 889.68296, E6: 0.00672 }\end{array}$ \\
\hline Cows & 269.10386 & -11.85909 & \\
\hline Feedstuff & 2.70035 & $1.22526 \mathrm{E}-05$ & \\
\hline Land & -4609.10832 & 474.94612 & \\
\hline Roughage & 20.27928 & 0.00236 & \\
\hline
\end{tabular}

Not consistent with economic theory is indicated in bold

far, an empirical application is given subsequently. Using cross-sectional data on two different groups of production units we are interested in the relative technical efficiency of the two groups and the effects of imposing functional 
regularity. ${ }^{17}$ We use a simple model based on Kumbhakar (1989) and Sauer and Frohberg (2006) and compare the estimation outcome for different functional specifications. The production structure of a representative sample of producers is therefore assumed to be described by:

$$
y_{j}=f\left(x_{i j}, \beta_{i} ; D_{j}, \zeta_{k}\right)+\varepsilon_{j}
$$

with $y$ denoting the output produced by the $j$-th producer using the inputs $x_{i}$ where $i=$ input 1 , input 2 , and input 3 . One group of producers are subject to the exogenous determinant D (e.g. a climatic shock or unforeseen policy events) modelled in the form of a binary dummy variable taking the value 1 for the observations subject to the determinant and 0 otherwise. $\beta$ and $\zeta$ denote the parameters with respect to the explanatory variables. The disturbance term $\varepsilon_{j}$ has zero mean and constant variance. The production function is 'corrected' with respect to the 'best' group of production units by calculating the relative technical inefficiency $\hat{o}$ of group $k$ :

$$
\tau_{k}=\zeta_{k}-\min _{k}\left(\zeta_{k}\right)
$$

As we use only two groups the frontier is defined by the technology of the 'best' sub-sample and $\tau_{k}$ can be interpreted as the relative efficiency difference between the two groups of producers. The model in (7) is estimated by applying different functional specifications: the translog (TL), the generalized Leontief (GL), the symmetric generalized McFadden (SGM), the symmetric generalized Barnett (SGB) as well as the parametrically estimated asymptotically ideal production model of order 2 (AIM2). The stochastic efficiency model is estimated in an unrestricted version, by imposing local monotonicity, by imposing local or global quasi-concavity, by imposing local monotonicity as well as global quasiconcavity, and by imposing local or global regularity. The corresponding model specifications as well as the estimation results are given by Table 17 .

The estimation results reveal the stark differences in the relative efficiency estimates obtained by unrestricted and restricted model specifications. This holds with respect to all functional forms tested. From a purely statistical perspective the translog specification shows the best fit for the unrestricted version (TL0). From a purely theoretical perspective the symmetric generalized Barnett specification shows the lowest number of violations in its locally monoton and globally quasi-concave version (SGB3). However, the effect of theoretical restrictions on the efficiency difference between the two groups of producers is the greatest for the translog functional form (TL0 to TL2) and the lowest for

17 The exemplary cross-sectional sample consists of agricultural production data on maize production in Malawi for the year 2003. The exogenous determinant represents the different soil fertility management practices applied. 
Table 17 Flexible functional forms and efficiency measurement - summary statistics

\begin{tabular}{lllll}
\hline Functional specification $^{\mathrm{a}}$ & $\begin{array}{l}F \text {-Value } \\
\text { (level } \\
\text { of significance) }\end{array}$ & $\begin{array}{l}\text { Number of } \\
\text { monotonicity } \\
\text { violations } \\
(\mathrm{N}=252)\end{array}$ & $\begin{array}{l}\text { Number of } \\
\text { quasi-concavity } \\
(\mathrm{N}=252)\end{array}$ & $\begin{array}{l}\text { Efficiency } \\
\text { difference } \\
\text { (in \%) }\end{array}$ \\
\hline
\end{tabular}

\section{Translog (TL)}

$y=a_{0}+\sum_{i=1}^{n} a_{i} \ln x_{i}+\frac{1}{2} \sum_{i=1}^{n} \sum_{j=1}^{n} a_{i j} \ln x_{i} x_{j}$

$\begin{array}{lllll}\text { TL0 - unrestricted } & 3450.54^{\mathrm{b}} & 252 & 252 & 95.06 \\ \text { TL1 - local monotonicity } & 1171.82^{\mathrm{b}} & 33 & 33 & 58.74 \\ \text { TL2 - local quasi-concavity } & 1193.62^{\mathrm{b}} & 33 & 33 & 49.40 \\ \text { TL3 - local regularity } & 1175.77^{\mathrm{b}} & 34 & 32 & 49.90\end{array}$

\section{Generalized Leontief (GL)}

$y=\sum_{i=1}^{n} b_{i} \sqrt{x_{i}}+\sum_{i=1}^{n} \sum_{j=1}^{n} b_{i j} \sqrt{\left(x_{i} x_{j}\right)}$

GL0 - unrestricted $\quad 69.66^{\mathrm{b}}$

GL1 - local monotonicity $\quad 20.25^{\mathrm{b}}$

$69.66^{\mathrm{b}}$
$20.25^{\mathrm{b}}$
$19.87^{\mathrm{b}}$

GL2 - local quasi-concavity

$19.87^{\mathrm{b}}$

$0 \quad 252$

75.24

$50 \quad 75.24$

GL3 - local regularity

$17.95^{\mathrm{b}}$

67

75.08

Symmetric Generalized McFadden (SGM)

$94 \quad 70.43$

$y=\sum_{i=1}^{n} \beta_{i} x_{i}+\frac{1}{2}\left(\sum_{i=1}^{n} \theta_{i} x_{i}\right)^{-1} \sum_{i=1}^{n} \sum_{j=1}^{n} \varphi_{i j}\left(x_{i} x_{j}\right)$

SGM0 - unrestricted $\quad 111.02^{\mathrm{b}} \quad 252$

SGM1 - local monotonicity $\quad 25.27^{\mathrm{b}} \quad 212$

201

85.15

SGM2 - global quasi-concavity

$110.00^{\mathrm{b}} \quad 252$

158

83.27

SGM3 - local monotonicity,

$25.05^{\mathrm{b}}$

252

0

85.38

global quasi-concavity

0

83.66

Symmetric Generalized Barnett (SGB)

$y=2 \sum_{i=1}^{n} \sum_{j=1, j>i}^{n} b_{i j} \sqrt{\left(x_{i} x_{j}\right)}+\sum_{i=1}^{n} \beta_{i} x_{i}$

$\begin{array}{lllll}\text { SGB0 - unrestricted } & 100.72^{\mathrm{b}} & 101 & 252 & 75.24 \\ \text { SGB1 - local monotonicity } & 23.68^{\mathrm{b}} & 101 & 252 & 99.97 \\ \text { SGB2 - global quasi-concavity } & 100.64^{\mathrm{b}} & 94 & 0 & 75.17 \\ \text { SGB3 - local monotonicity, } & 23.35^{\mathrm{b}} & 34 & 0 & 99.97\end{array}$

global quasi-concavity

\section{Asymptotically Ideal Production Model [2] (AIM2)}

$$
\begin{array}{lllll}
y=\sum_{i=1}^{n} \beta_{i} x_{i}+\sum_{i=1}^{n} \sum_{j=1, j \neq i}^{n} \alpha_{i j} x_{l}^{\frac{1}{2}} x_{j}^{\frac{1}{2}}+\sum_{i=1}^{n} \sum_{j=1, j \neq i}^{n} x_{i j} x_{i}^{\frac{3}{4}} x_{j}^{\frac{1}{4}}+\sum_{i=1}^{n} \sum_{j=1, j \neq i}^{n} \delta_{i j} x_{i}^{\frac{1}{4}} x_{j}^{\frac{3}{4}} \\
\quad+\varphi_{1123} x_{l}^{\frac{1}{2}} x_{j}^{\frac{1}{4}} x_{k}^{\frac{1}{4}}+\varphi_{1223} x_{i}^{\frac{1}{4}} x_{j}^{\frac{1}{2}} x_{k}^{\frac{1}{4}}+\varphi_{1233} x_{i}^{\frac{1}{4}} x_{j}^{\frac{1}{4}} x_{k}^{\frac{1}{2}} \\
\text { AIM(2)0 - unrestricted } & 0.04 & 225 & 219 & \\
\operatorname{AIM}(2) 1 \text { - local monotonicity } & 5.06^{\mathrm{b}} & 251 & 127 & 21.39 \\
\operatorname{AIM}(2) 2 \text { - local quasi-concavity } & 11.36^{\mathrm{b}} & 2 & 62 & 73.18 \\
\operatorname{AIM}(2) 3 \text { - local regularity } & 11.65^{\mathrm{b}} & 35 & 96 & 76.17
\end{array}
$$

\footnotetext{
${ }^{a}$ Notes: Sample size is 252 . All models were estimated by nonlinear estimation. The point of local approximation is the sample mean. Local quasi-concavity was imposed at the point of approximation by Cholesky decomposition of the Hessian, global quasi-concavity was imposed by Cholesky decomposition of the global Hessian

b Significance of the model specification at the $1 \%$-level. With respect to functional flexibility the Translog, Generalized Leontief, and the Asymptotically Ideal Production Model can only be restricted for local regularity. The Symmetric Generalized McFadden as well as the Symmetric Generalized Barnett can be restricted for global quasi-concavity but lose their flexibility if restricted for global monotonicity
} 


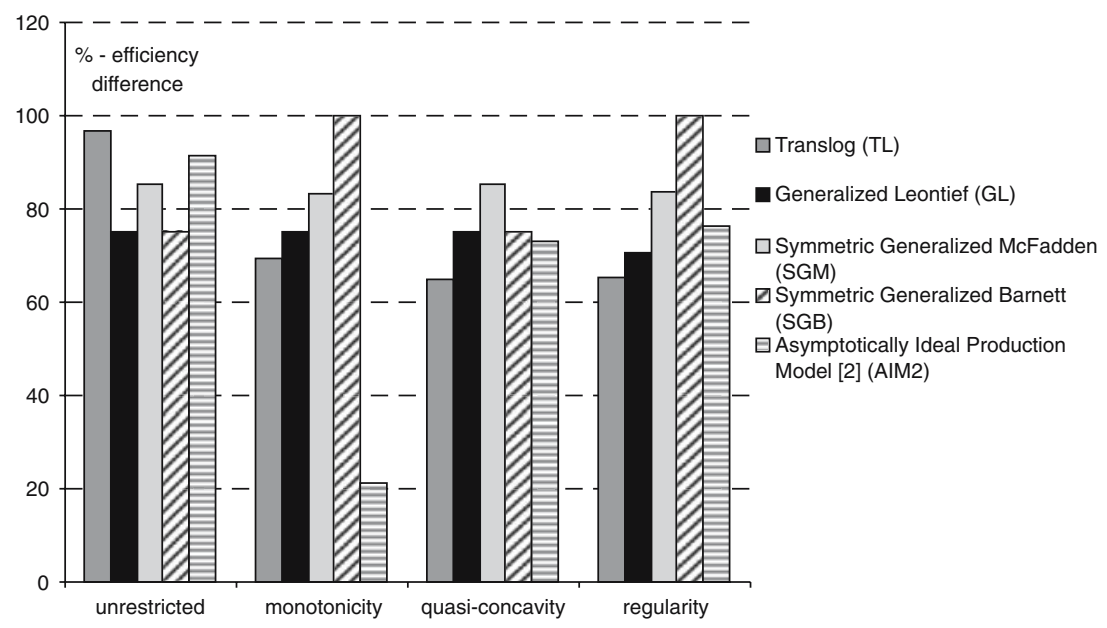

Fig. 5 Efficiency difference - variation per functional specification

the generalized Leontief (GL0 to GL1). Figure 5 illustrates the variation in the estimated efficiency difference for the various model specifications.

\subsection{Testing for regularity by stochastic resampling}

In order to test for the robustness of the estimates and the validity of the conlcusions drawn a bootstrapping technique is used to create 50 pseudoreplicate datasets for every functional form specification. Hereby it is possible to assess whether the distribution of characters has been influenced by stochastic effects. ${ }^{18}$ Tables 18,19 and 20 give a summary statistic for the efficiency values, the correct curvature, and monotonicity range (see also Appendix).

Whereas the most robust estimates with respect to efficiency can be reported for the restricted symmetric generalized Barnett (SGB3) specification, the least robust ones were revealed by the simulations for the restricted translog (TL3) specification. The bootstrapping procedure showed the highest range of functional quasi-concavity beside the globally restricted SGM and SGB specifications for the locally restricted translog (TL3). The most robust estimates can be reported beside the globally restricted functional forms for the restricted AIM(2) specification, the lowest for the unrestricted SGM specification. The restricted generalized Leontief specification (GL3) showed the highest range of monotonicity, the unrestricted translog specification (TL0) the lowest range. Both specification, however, deliver the most robust estimates. Finally Kernel density distributions for the locally restricted functional forms with respect to

\footnotetext{
18 The bootstrapping procedure included in STATA8.0 was used. See for the theoretical background e.g. Hastie et al. (2001).
} 
Table 18 Bootstrap simulations - efficiency

\begin{tabular}{lrrl}
\hline Specification & \multicolumn{3}{l}{ Efficiency $(\%)$} \\
\cline { 2 - 4 } & Mean & Stdev & $95 \%$, Confidence interval \\
\hline TL0 - unrestricted & 94.57 & 1.24 & {$[94.23 ; 94.91]$} \\
TL3 - local regularity & 32.61 & 18.04 & {$[27.66 ; 37.56]$} \\
GL0 - unrestricted & 61.19 & 5.96 & {$[59.56 ; 62.83]$} \\
GL3 - local regularity & 54.28 & 5.79 & {$[52.70 ; 55.87]$} \\
SGM0 - unrestricted & 84.83 & 2.35 & {$[84.18 ; 85.47]$} \\
SGM3 - local monotonicity, global quasi-concavity & 83.37 & 2.20 & {$[82.76 ; 83.97]$} \\
SGB0 - unrestricted & 74.92 & 2.64 & {$[74.20 ; 75.65]$} \\
SGB3 - local monotonicity, global quasi-concavity & 99.97 & 0.00 & n.a. \\
AIM(2)0 - unrestricted & 89.98 & 5.00 & {$[88.61 ; 91.36]$} \\
AIM(2)3 - local regularity & 88.94 & 5.54 & {$[87.42 ; 90.46]$} \\
\hline
\end{tabular}

Table 19 Bootstrap simulations - quasi-concavity

\begin{tabular}{lccl}
\hline Specification & \multicolumn{3}{c}{ Range of quasi-concavity $(\%)$} \\
\cline { 2 - 4 } & Mean & Stdev & $95 \%$, Confidence interval \\
\hline TL0 - unrestricted & 2.18 & 9.47 & {$[0.00 ; 4.78]$} \\
TL3 - local regularity & 78.05 & 16.10 & {$[73.63 ; 82.47]$} \\
GL0 - unrestricted & 1.13 & 2.45 & {$[0.46 ; 1.80]$} \\
GL3 - local regularity & 61.20 & 5.96 & {$[59.91 ; 62.50]$} \\
SGM0 - unrestricted & 36.10 & 28.89 & {$[28.45 ; 43.76]$} \\
SGM3 - local monotonicity, & & & \\
global quasi-concavity & 100.00 & 0.00 & n.a. \\
SGB0 - unrestricted & 0.36 & 1.55 & {$[0.00 ; 0.78]$} \\
SGB3 - local monotonicity, & & & \\
global quasi-concavity & 100.00 & 0.00 & n.a. \\
AIM(2)0 - unrestricted & 12.77 & 1.83 & {$[12.27 ; 13.27]$} \\
AIM(2)3 - local regularity & 47.49 & 5.82 & {$[45.90 ; 49.09]$} \\
\hline
\end{tabular}

the relative range of functional consistency were estimated and are given in the Appendix. ${ }^{19}$

Figure 6 impressively documents that there is a significant effect on the efficiency estimates for every functional form and sample by the curvature of the functional form. This is empirical proof for the concerns expressed in the more theoretical part of this paper. Imposing theoretical consistency hence always affects the approximated relative efficiency of the production units analysed. This was found to be less severe for the globally restrictable symmetric generalized McFadden as well as the asymptotically ideal production model of order 2.

$\overline{19}$ See for the theoretical background e.g. Greene (2001). 
Table 20 Bootstrap simulations - monotonicity

\begin{tabular}{lrrl}
\hline Specification & \multicolumn{3}{l}{ Range of Monotonicity (\%) } \\
\cline { 2 - 4 } & Mean & Stdev & $95 \%$, Confidence interval \\
\hline TL0 - unrestricted & 0.00 & 0.00 & n.a. \\
TL3 - local regularity & 93.03 & 6.32 & {$[91.29 ; 94.76]$} \\
GL0 - unrestricted & 96.28 & 15.63 & {$[91.99 ; 100.00]$} \\
GL3 - local regularity & 100.00 & 0.00 & n.a. \\
SGM0 - unrestricted & 13.35 & 28.14 & {$[5.63 ; 21.08]$} \\
SGM3 - local monotonicity, global quasi-concavity & 1.31 & 1.16 & {$[0.99 ; 1.62]$} \\
SGB0 - unrestricted & 49.30 & 14.67 & {$[45.27 ; 53.33]$} \\
SGB3 - local monotonicity, global quasi-concavity & 77.41 & 17.78 & {$[72.53 ; 82.29]$} \\
AIM(2) - unrestricted & 1.23 & 4.12 & {$[0.10 ; 2.36]$} \\
AIM(2) - local regularity & 4.51 & 14.10 & {$[0.64 ; 8.38]$} \\
\hline
\end{tabular}

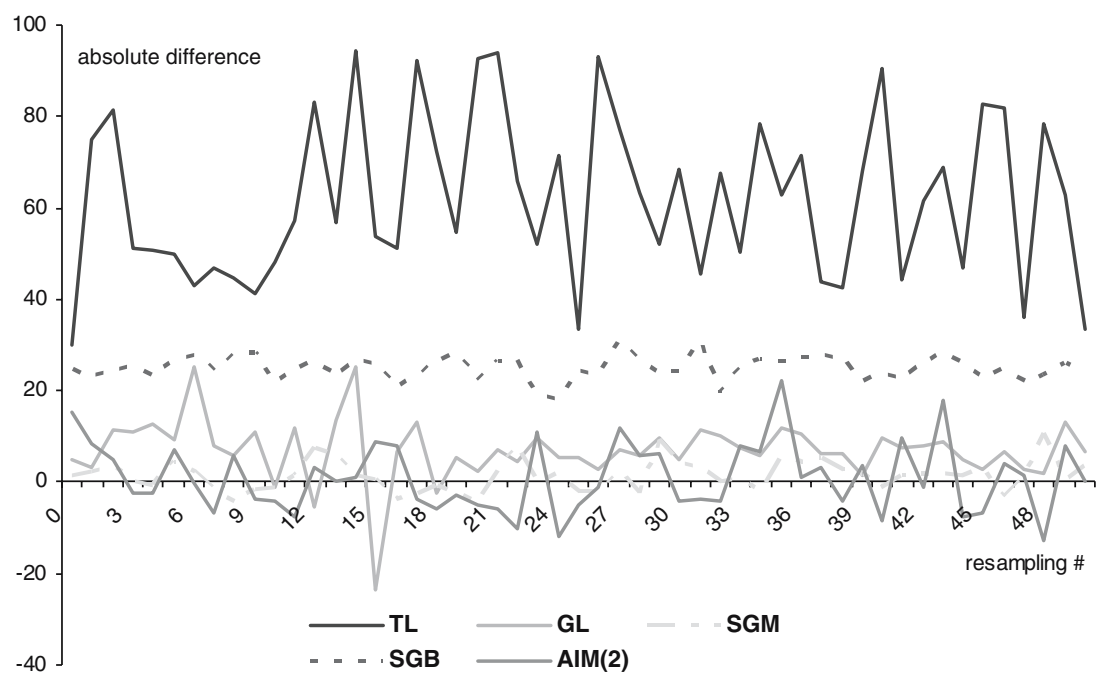

Fig. 6 Absolute difference in efficiency - bootstrapped samples

\section{Conclusions}

This contribution aims to shed light on the link between microeconomic theory and econometric practice with respect to parametric efficiency analysis. Theoretical concerns are verified by empirical applications. The results highlight the compelling need for a critical assessment of the estimates with respect to the current evidence on theoretical consistency, flexibility as well as the choice of the appropriate functional form. The majority of existing studies do not 
adequately test for whether the estimated function has the required regularities of monotonicity and quasi-concavity, and hence run the risk of making improper policy recommendations. The researcher has to check a posteriori for the regularity of the estimated frontier which means checking these requirements for each and every data point. If these requirements do not hold they have to be imposed a priori to estimation. Imposing global regularity, however, leads to a significant loss of functional flexibility with respect to the majority of flexible functional forms. The imposition of local regularity requires a differentiated interpretation: if theoretical consistency holds for a range of observations, this 'consistency area' of the estimated frontier should be determined and clearly stated. Estimated relative efficiency scores hence only hold for observations which are part of this range. Alternatively flexible functional forms - as e.g. the symmetric generalized McFadden or the symmetric generalized Barnett - could be used. These functional forms can be easily accomodated to global quasi-concavity over the whole range of observations. Bootstrapping based stochastic simulations of a simple parametric efficiency model by using different flexible functional forms confirmed the severeness of the theoretical concerns especially with respect to the only locally restrictable translog specification.

Acknowledgements The author thanks Klaus Frohberg and Heinrich Hockmann for helpful comments as well as Hardwick Tchale for generously allowing access to the data set. He is also indebted to an anonymous referee and an co-editor, Baldev Raj, for valuable suggestions improving the final paper.

\section{Appendix: Negative semi-definiteness of a matrix}

Any symmetric matrix $\mathbf{M} \in \mathrm{R}^{\mathrm{n}} \times \mathrm{R}^{\mathrm{n}}$ is negative semi-definite (nsd) if and only if

$$
Q(M, Z)=Z^{\prime} M Z \leq 0
$$

for arbitrary $\mathbf{Z} \in \mathrm{R}^{\mathrm{n}}$. The $\mathbf{Q}(\mathbf{M}, \mathbf{Z})$ is referred to as the quadratic form of the symmetric matrix $\mathbf{M}$. If $\mathbf{Q}(\mathbf{M}, \mathbf{Z})<0, \mathbf{M}$ is called 'negative definite'.

\section{Lemma $\mathbf{A 1} Q(M, Z)$ is nsd only if}

(a) its principal minors (i.e. determinants) alternate in sign starting with a negative number,

(b) its principal submatrices are $n s d$, and

(c) the diagonal elements of $\boldsymbol{M}\left(m_{i j}\right)$ are nonpositive (i.e. $\left.m_{i j}<0\right)$.

(d) $\boldsymbol{Q}(\boldsymbol{M}, \boldsymbol{Z})$ of the rank $>3 \times 3$ is nsd if for all eigenvalues $\boldsymbol{e}$ of $\boldsymbol{Q}: \boldsymbol{e} \leq 0$ (Figs. 7, 8 and 9). 


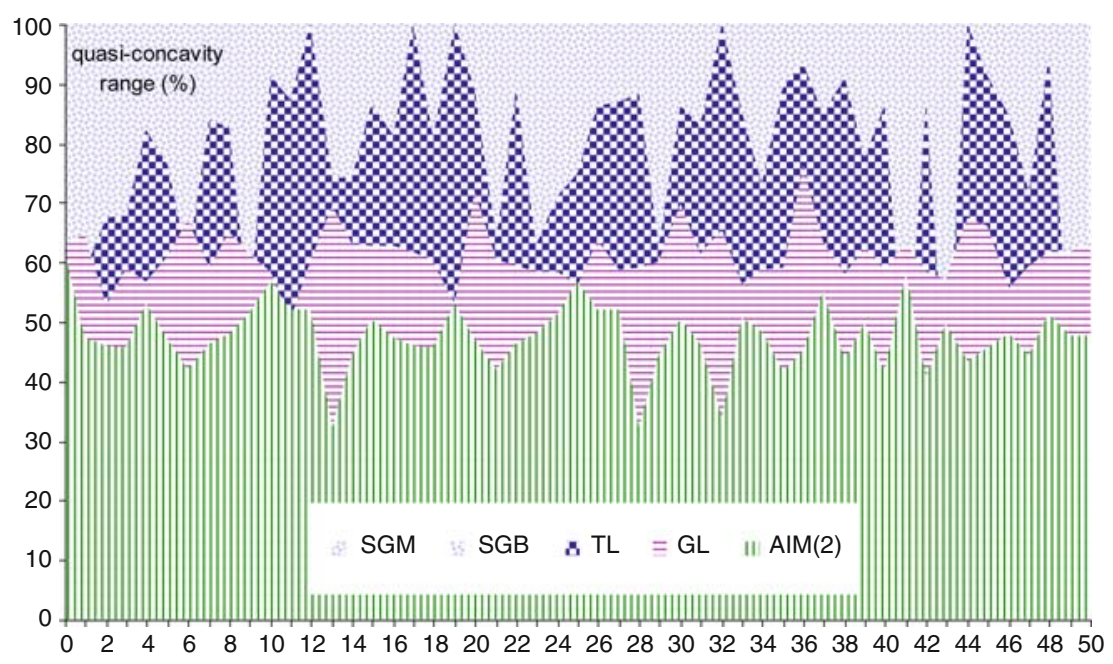

Fig. 7 Quasi-concavity ranges/bootstrapped samples

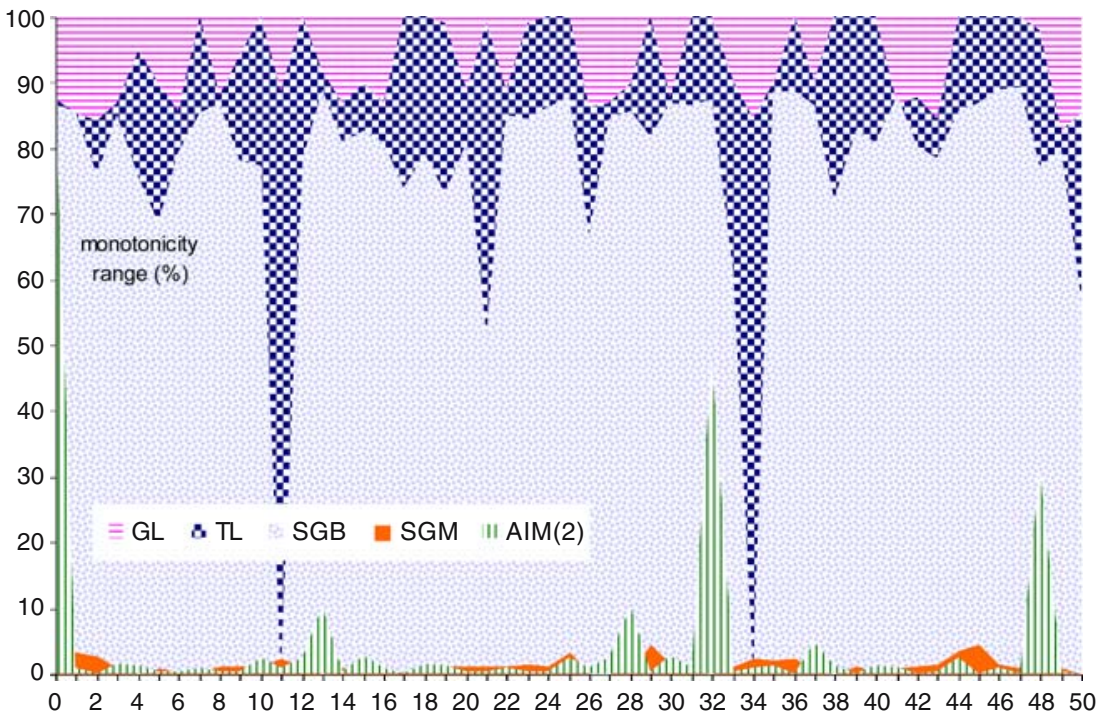

Fig. 8 Monotonicity ranges/bootstrapped samples 

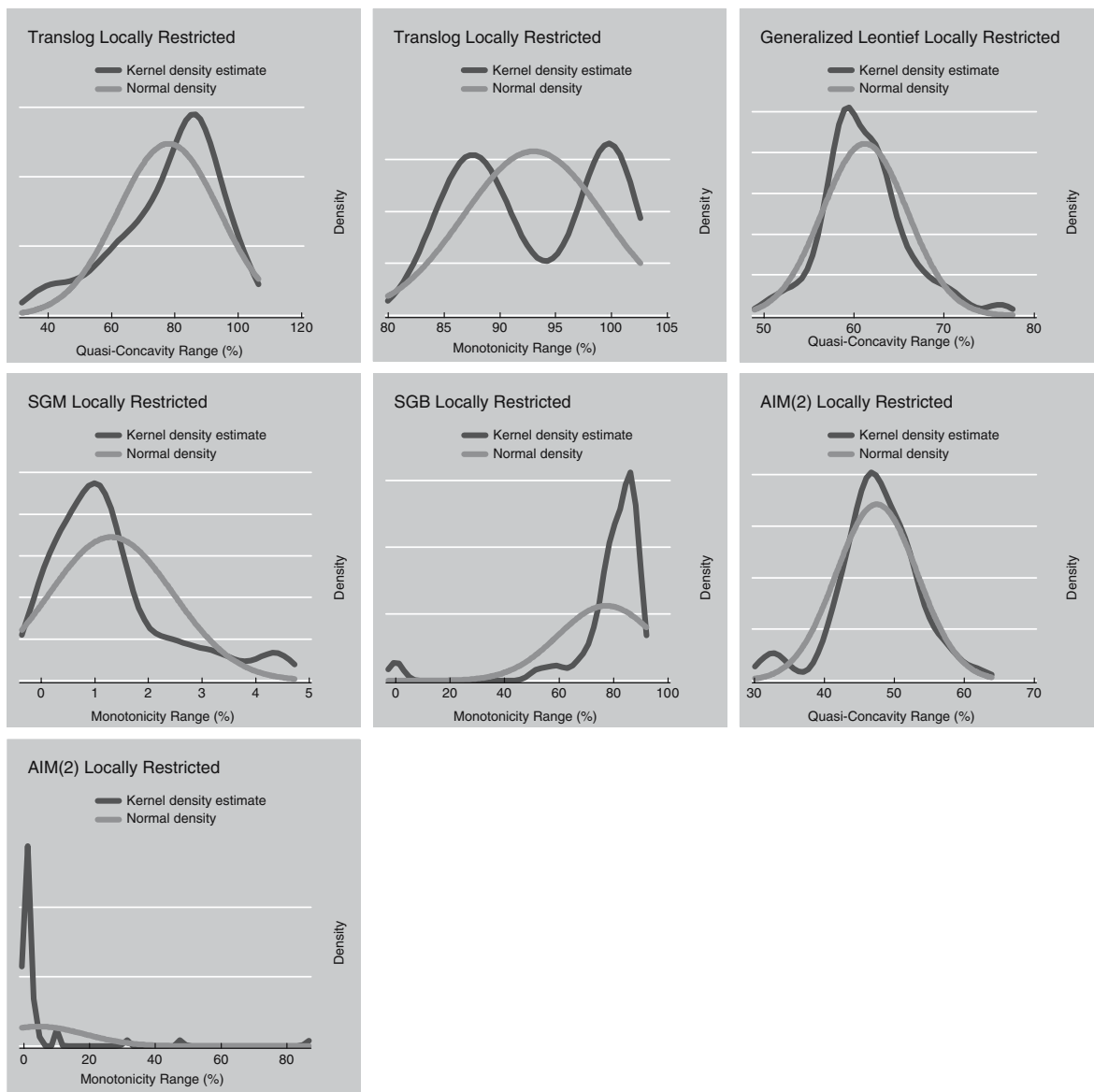

Fig. 9 Kernel density distributions for local functional consistency

\section{References}

Ajibefun IA, Battese GE, Daramola, AG (2002) Determinants of technical efficiency in smallholder food crop farming: application of stochastic frontier production function. Q J Int Agric 41:225-240

Alvarez A, Arias C (2004) Technical efficiency and farm size: a conditional analysis. Agric Econ 30:241-250

Anderson RG, Jones B, Nesmith T (1996) An introduction to monetary aggregation theory and statistical index numbers. Federal Reserve Bank of St. Louis, Research Division Working Papers 9, St. Louis

Banker RD, Janakiraman S, Natarajan R (2002) Evaluating the adequacy of parametric functional forms in estimating monotone and concave production functions. J Product Anal 17:111-132

Barnett WA (2002) Tastes and technology: curvature is not sufficient for regularity. J Econom 108:199-202

Barnett WA (2004) Functional structure and approximation in econometrics. Elsevier, Amsterdam

Barnett WA, Kirova M, Pasupathy M (1996) Estimating policy invariant deep parameters in the financial sector, when risk and growth matter. J Money Credit Bank 27:1402-1430 
Battese GE, Broca SS (1997) Functional forms of stochastic frontier production functions and models for technical inefficiency effects: a comparative study for wheat farmers in pakistan. J Product Anal 8:395-414

Blackorby C, Diewert WE (1979) Expenditure functions, local duality, and second order approximations. Econome 47:579-601

Brümmer B (2001) Estimating confidence intervals for technical efficiency: the case of private farms in slovenia. Euro Rev Agric Econ 28:285-306

Brümmer B, Loy JP (2000) The technical efficiency impact of farm credit programmes: a case study of northern germany. J Agric Econ 51:405-418

Casler SD (1997) Applied production theory: explicit, flexible and general functional forms. Appl Econ 29:1483-1492

Chambers R (1988) Applied production analysis: a dual approach. Cambridge University Press, Cambridge

Christopoulos D, Loizides J, Tsionas EG (2001) Efficiency in European Railways: not as inefficient as one might think. J Appl Econ 4:63-88

Craig S (2002) The Effect of institutional form on airport governance efficiency. Department of Economics, University of Houston, Houston

Diewert EW (1973) Functional forms for profit and transformation functions. J Econ Theory 6:284-316

Diewert EW (1974) Functional forms for revenue and factor requirements. Int Econ Rev 15:119-130

Diewert WE, Wales TJ (1987) Flexible functional forms and global curvature conditions. Econometrica 55:43-68

Feger F (2000) A behavioural model of the German compound feed industry: functional form, flexibility, and regularity, Göttingen

Frohberg K, Winter E (2003) Impacts of Croatia's Bi- and multilateral trade agreements: experiments with different trade model specifications. Zentrum für Entwicklungsforschung, University of Bonn, Bonn, Germany

Fuss M, McFadden D (1978) Production economics: a dual approach to theory and applications, vol 1. The theory of production, vol 2. Applications of the theory of production. North-Holland, New York

Fuss M, McFadden D, Mundlak Y (1978) A survey of functional forms in the economic analysis of production. In: Fuss M, McFadden D (eds) Production economics: a dual approach to theory and applications, vol 1. The theory of production. North-Holland, New York, pp 219-268

Gallant AR, Gollup GH (1984) Imposing curvature restrictions on flexible functional forms. J Econom 26:295-321

Giannakas K, Tran KC, Tzouvelekas V (2003) On the choice of functional form in stochastic frontier modelling. Empir Econ 28:75-100

Greene WH (2003) Econometric analysis. International Edition. Prentice Hall

Hastie T, Tibshirani R, Friedman J (2001) The elements of statistical learning. Springer, Berlin Heidelberg New York

Hanoch G (1970) Generation of new production functions through duality. Harvard Institute of Economic Research, Discussion Paper 118, Cambridge Mass

Jorgenson DW, Fraumeni BM (1981) Relative prices and technical change. In: Berndt ER (ed) Modeling and measuring natural resource substitution. MIT Press, Cambridge, pp 17-47

Kumbhakar S (1989) Estimation of technical efficiency using flexible functional form and panel data. J Bus Econ Stat 7:253-258

Kumbhakar SC, Heshmati A (1995) Efficiency measurement in swedish dairy farms: an application of rotating panel data 1976-88. Am J Agric Econ 77:660-674

Kumbhakar SC, Hjalmarsson L (1993) Technical efficiency and technical progress in swedish dairy farms. In: Fried $\mathrm{HO}$ (ed) The measurement of productive efficiency - techniques and applications. New York, Oxford, pp 256-270

Kwon OS, Lee H (2004) Productivity improvement in korean rice farming: parametric and nonparametric analysis. Aust J Agric Resour Econ 48:323-346

Lau LJ (1978) Testing and imposing monotonicity, convexity and quasi-convexity constraints. In: Fuss M, McFadden D (eds) Production economics: a dual approach to theory and applications, vol 1. The theory of production, vol 2. Applications of the theory of production. North-Holland, New York 
Lau LJ (1986) Functional forms in econometric model building. In: Griliches Z, Intriligator MD (eds) Handbook of econometrics, vol III. North-Holland Elsevier, New York, pp 1516-1566

Marcus M, Minc H (1988) Introduction to linear algebra, Dover, New York

Morey ER (1986) An introduction to checking, testing, and imposing curvature properties: the true function and the estimated function. Can J Econ 19:207-235

O'Donnell CJ (2002) Parametric estimation of technical and allocative efficiency in US agriculture. In: Ball E, Norton GW (eds) Agricultural productivity: measurement and sources of growth. Kluwer, Boston, pp 137-166

Pierani P, Rizzi P (2001) Technology and efficiency in a panel of Italian dairy farms: a SGM Restricted Cost Function Approach, Manuscript, Department of Economics, University of Siena, Siena, Italy

Rask K (1995) The structure of technology in Brazilian sugarcane production 1975-87 - an application of a modified symmetric generalized McFadden cost function. J Appl Econom 10:221-232

Ryan DL, Wales TJ (1998) A simple method for imposing local curvature in some flexible consumer demand systems. J Bus Econ Stat 16:331-338

Ryan DL, Wales TJ (1999) Flexible and semiflexible consumer demands with quadratic engel curves. Rev Econ Stat 81:277-287

Ryan DL, Wales TJ (2000) Imposing local concavity in the translog and generalized leontief cost functions. Econ Lett 67:253-260

Salvanes KG, Tjotta S (1998) A note on the importance of testing for regularities for estimated flexible functional forms. J Product Anal 9:133-143

Sauer J, Frohberg K (2006) Input specific allocative efficiency of rural water suppliers - a flexible and globally concave cost frontier. J Product Anal (forthcoming)

Skinner J (1994) What do stochastic frontier cost functions tell us about Inefficiency? J Health Econ 13:323-328

Strang G (1976) Linear algebra and its applications. Academic, New York

Terrell D (1996) Incorporating monotonicity and concavity conditions in flexible functional forms. J Appl Econ :179-194

Thiam A, Bravo-Ureta BE, Rivas TE (2001) Technical efficiency in developing country agriculture: a meta-analysis. Agric Econ 25:235-243

Tzouvelekas E (2000) Approximation properties and estimation of the translog production function with panel data. Agric Econ Rev 1:27-41

Wales TJ (1977) On the flexibility of flexible functional forms. J Econ :183-193

Wiley DE, Schmidt WH, Bramble WJ (1973) Studies of a class of covariance structure models. J Am Stat Assoc 68:317-323

Zellner A, Ryu H (1998) Alternative functional forms for production, cost and returns to scale functions. J Appl Econ 13:101-127 